\title{
Evaluation of Mechanical Properties of Cement Composites With Nanomaterials
}

\author{
I. $\mathrm{CHOI}^{1}$, J. KIM ${ }^{2}$ AND C. CHUNG ${ }^{3 *}$
}

${ }^{1}$ Dept. of Architecture Engineering, Pukyong National Univ., Busan, Republic of Korea (gatooso05@naver.com)

${ }^{2}$ Multidisciplinary Infra-technology Research Laboratory, Pukyong National Univ. Busan, Republic of Korea (kjh@pknu.ac.kr)

${ }^{3}$ Dept. of Architecture Engineering, Pukyong National Univ., Busan, Republic of Korea (cwchung@pknu.ac.kr)

\section{Mechanical properties of Cement Paste}

It is known that physical and chemical changes of cement hydrate cause problems in the volume stability of concrete. In order to overcome these problems, there is a growing interest in research on mixing technology of cement-based materials and nanomaterials. So we compared mechanical properties of cement paste with various nanomaterials. Carbon nanotubes and Graphene Oxide are known to have superior mechnical properties, The research using Single walled Carbon nanotube, Multi walled Carbon nanotube and Graphene Oxide. In this study, first we prepared a dispersion solution to use nanomaterials. We used 2 types of surfactant. The first is DOC, a surfactant already used to disperse nanomaterials, and another one is a superplasticizer used in construction site. And then we measured the compressive strength to compare the mechanical properties. So our mix proportion is shown in the table below.

\begin{tabular}{|l|l|}
\hline W/C & 0.35 \\
\hline \multirow{3}{*}{ Nanomaterials } & Single walled carbonnanotube \\
\cline { 2 - 2 } & Multi walled carbon nanotube \\
\cline { 2 - 2 } & Graphene Oxide \\
\hline \multirow{2}{*}{ Surfactant } & Superplasicizer \\
\cline { 2 - 2 } & Sodium deoxycholate \\
\hline
\end{tabular}

Table 1: Table used to display mix proportion of cement paste. 